\title{
Revenue Determinants for Abu-Dhabi Fishermen and Assessment of Input Allocative Efficiency
}

\author{
Sherin A. Sherif* and Mohamed S. Gheblawi \\ Department of Agribusiness and Consumer Science \\ UAE University, Al-Ain, P.O. Box 17555, UAE \\ محددات العائد لصائدي الأسماك في أبو ظبي وتقييم الكفاعة السعرية لمدخلات الإنتاج \\ شـيرين شريف و محمد القبلاوي

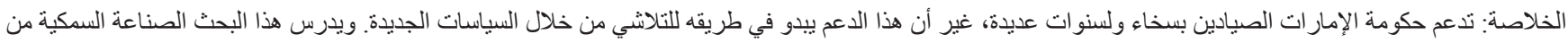

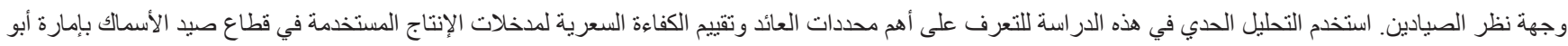

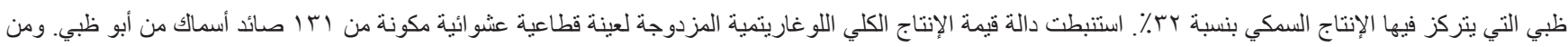

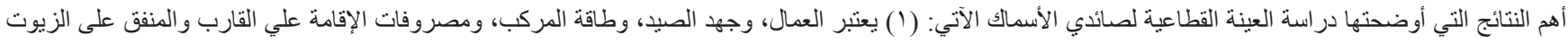

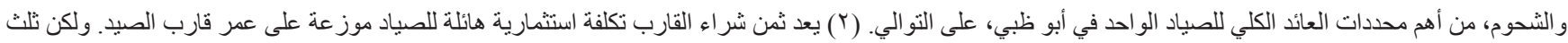

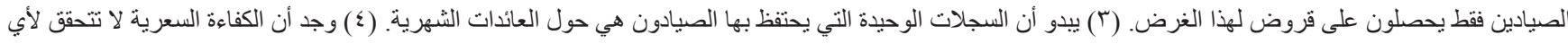

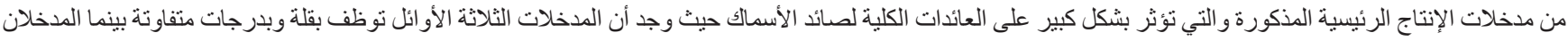

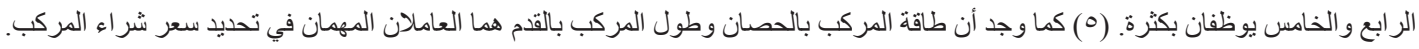 \\ كلمات مفتاحية: الصناعة السمكية بأبو ظبي ، الكفاءة السعرية ، محددات العائد
}

\begin{abstract}
This study examined the fishing industry in Abu Dhabi, the main fish-producing Emirate in the UAE, from the fishermen's point of view. Marginal analysis was used to identify the most prominent fishing-revenue determinants along with assessing the allocative (price) efficiency of inputs used. A log-log total value product (TVP) function was estimated for a representative cross-section random sample of $131 \mathrm{Abu}-\mathrm{Dhabi}$ fishermen. This revealed that (1) labor, fishing effort, boat capacity, boat boarding expenses, and expenditures on oil and lubricants are the five main determinants of total revenue for the individual fishermen in Abu Dhabi; (2) boat-purchase price constituted a huge investment cost to fishermen distributed over the lifetime of the boat; although only one-third of fishermen acquire loans for this purpose; (3) the only type of records fishermen keep were those pertinent to monthly revenues; and (4) price efficiency is found not to be achieved for any of the five prominent inputs that have great impact on total fishermen's revenues, as three inputs were found to be under-utilized in varying degrees, whereas two were found to be significantly over-utilized.
\end{abstract}

Keywords: Abu-Dhabi fishing industry, allocative efficiency, revenue determinants.

\section{Introduction}

Fishing is the oldest industry in the UAE, along with pearl extraction, yet little information about it is publicly available and the recording of time-series data started only in 1998. The UAE Government has generously supported fishermen over the years with a tendency towards gradual reduction of support as a general government policy. During the period 1997-2003, on average, fish production in the UAE contributed $12 \%$ to the value of agricultural production. In 2003, the value of fish production was about AED 1.1 billion (one US Dollar equals AED 3.675), with an annual growth rate of $15 \%$ since 1999 . UAE production of pelagic and demersal fish amounted to 103,255 tons in 2003, whereas the catch from crustaceans reached 2,201 tons. Total fish production has been steady between 1997 and 2003 at an average of 112.5 thousand tons (Ministry of Environment and Water, 2004).
Fish production is concentrated in four main regions of UAE: Abu Dhabi (32\% of UAE's fish production), the Central Region (27\%), the Eastern Region (22\%), and the Northern Region (17\%). Between 1999 and 2003, the number of people engaged in fishing as full or part timers increased by about $53 \%$, from 10,172 to 15,543 individuals. For the same period, the total number of fishing boats increased by about $40 \%$, from 3,321 to 4,688 boats (FAO, 2003).

Given the importance of fish as a source of livelihood to many Emiratis, the lack of information on this industry, the anticipated government withdrawal from supporting the industry, and the non-existence of economic studies on the UAE's fishing resources in general, and fishermen as individual producers in particular, it is important to examine the industry from a microeconomic perspective. This paper's main objective is to examine the economic

*Corresponding author. E-mail: sherin.sherif@uaeu.ac.ae 
status and production practices of individual fishermen in the UAE's main Emirate of Abu Dhabi, where fish production is most concentrated, and to assess fishermen's economic efficiency. A comprehensive field survey that covered a representative cross-section random sample of the fishermen registered in the Fishing Cooperative of Abu Dhabi was conducted in the fall of 2006. This main objective was achieved through the identification of the different variable inputs utilized in the production process, the ranking of these inputs in terms of their relative importance to the value of output, the assessment of the responsiveness of the value of output to changes in input levels, and the assessment of price (allocative) efficiency of the most prominent inputs in the production process.

\section{Literature Review}

Several studies on the economics of fishing have been performed worldwide. Due to the dynamic nature of fishing problems and the lack of property rights in this industry in most if not all nations the common themes of fishing literature include the dynamics of overfishing, the inefficient allocation of resources and fishery pollution (FAO, 2004; and Ruseski, 1998).

These studies show that, for production to be efficient, inputs have to be used in proportion to their relative scarcity. In commercial fisheries, private producers turn to market mechanisms for allocating capital and manpower. This is not the case, however, for the resource as long as access is open and free. Under such conditions the resource value is not taken into account in allocating production factors. Resources are used as though they were inexhaustible. As long as resources are considered not constraining, the need for rationing their use is less critical (Jolly and Clonts, 1993).

Other studies adopted production function estimation and/or revenue factors configuration when addressing input-output relationships in the fishing industry and assessment of economic efficiency on the micro level by examining fishermen's behavior. For instance, Gupta (1983) attempted to study the input-output relationship in fish farming in India through the estimation of the production function and the derivation of the optimum input combination. He utilized cross-section data and found that fish farming was subject to constant returns to scale (doubling of inputs doubles output), production technology was far from optimum, and application of the optimum production technique reduced production costs and raised the profit rate.

Esmaeili (2006) examined the technical efficiency of the Iranian fishing industry and identified factors that could be causing inefficiency. A stochastic production function among fishery vessels was estimated. The results indicated that technical efficiency in the fishery was relatively low, wooden vessels of medium size were more efficient than small fiberglass vessels, vessel instrumentation had a significant impact on efficiency, and having a satellite connection on the boat and high level of education for the skipper were important considerations that influenced fishing efficiency.

Eggert (2000) examined the level and determinants of technical efficiency for a sample of Swedish demersal trawlers. The data on per-trip gross revenues, fishing effort, gear choice, month of fishing, and vessel attributes were analyzed using a translog stochastic production frontier, including a model for vessel-specific technical inefficiencies. Output elasticities and returns to scale were also examined. The technical inefficiency effects were found to be highly significant in explaining the levels and variation in vessel revenues. The inefficiency model indicated that fishermen were more efficient the more hours they fished, that older vessels were less efficient, while the size of vessel did not influence efficiency.

The above literature indicates that both the production function and the revenue approaches could be used interchangeably. The first approach was utilized when physical quantities of fish catch were known, whereas when revenues that result from this catch were obtained, total revenue functions were deployed. As stated earlier, the total value product function approach was implemented in this study.

\section{Materials and Methods}

By definition, and according to marginal analysis economic theory, the production function embodies technical or production efficiency information. It indicates the maximum amount of output obtainable from the utilization of a specific quantity of inputs, given the existing technology level governing the input-output relationship. The said input-output relationship is assumed to be known with certainty. Moreover, inputs included in the production function are assumed to be homogeneous, and prices of both inputs and outputs are assumed to be known with certainty.

Economic efficiency, on the other hand, refers to the combinations of inputs that maximize individual or social objectives. It is defined in terms of two conditions: necessary and sufficient. The first is met in the production process when estimating the production function. The second varies with the objectives of the individual fisherman. In most of the economic literature under perfect knowledge the individual fisherman's objective is assumed to be profit maximization, i.e. allocative efficiency. It is defined as profit maximization through equating the value of marginal product of the variable input to its unit price. In case a total value product function is estimated, when the physical quantity of output produced is not known and its corresponding value is known instead, the optimality condition (i.e. allocative efficiency condition) occurs where the marginal value product of the input (MVP) is equal to the marginal input cost (MIC) (Egna and Boyd, 1997, Grafton and Lane, 1998).

Inputs theoretically known to impact the level of output are boat capacity (in horsepower), fishing effort (in days), mesh size (in squared centimeters), labor (in man/days), 
fossil fuel (in monetary cost or physical amounts), food and boarding of boat crew (in monetary terms), stationary or movable fishing traps (in numbers or cubic meters), and equipment on board (connected or unconnected to satellite communication). In this study, data could not be collected for some of these inputs, however. There are, of course, other factors that affect profitability, such as maintenance, seasonality of fish types, fraud (when there are fewer fishing permits than fishing boats), fishing licenses, and pollution. These factors are not addressed in this study.

In addition to the use of some secondary data available on the fishing industry in Abu Dhabi, a comprehensive cross-section field-survey was designed to collect primary data from a random sample of fishermen who were registered in the Abu-Dhabi Fishermen's Cooperative. A total of 131 fishermen were interviewed in person, representing about $9 \%$ of the total population of fishermen who were registered in the Abu Dhabi Fishermen's Cooperative. The questionnaire was divided into four main sections: general information (22 questions), fixed costs (11 questions), inputs and variable costs (22 questions), and output and returns (9 questions).

\section{The Empirical Model}

Since the interviewed fishermen kept records on revenues and not on the amounts and types of commercial fish catch, the best empirical alternative was to estimate a total value product function (TVP), which is equivalent to a monthly total revenue function, which incorporates the total value of the fish catch per fisherman per month and the factors associated with that monthly revenue. Then an identification of the total revenue determinants rather than the production determinants was made.

The estimated total value product (revenue) function is a log-log function as follows:

$$
\begin{aligned}
& \ln \_\operatorname{RETN}=\mathrm{a}_{0}+\mathrm{a}_{1} \ln \_ \text {EFFORT }+\mathrm{a}_{2} \ln \_\mathrm{BHP}+\mathrm{a}_{3} \\
& \ln \_ \text {LABOR + } a_{4} \ln \text { BOARD + } \\
& \mathrm{a}_{5} \mathrm{Ln} \_\mathrm{OIL}+\mathrm{e} \text {..................(1) }
\end{aligned}
$$

where (ln_RETN) is total monthly revenues in AED or TVP as the dependent variable, and five independent variables affect total revenues, all in the logarithmic form: In_EFFORT, In_BHP, In_LABOR, In_BOARD, and ln_OIL, which respectively stand for fishing effort in fishing days (which is the outcome of multiplying the fishing times per month (FTIM) and the length of the fishing trip in days (TDAY)), boat capacity in horsepower, number of laborers on board, the boarding expenses of the fishing-boat crew in AED, and costs of oils and lubricants. On the other hand, $a_{i}(i=0$ to 5$)$ stands for the estimated regression coefficients while " $\mathrm{e}$ " is the equation error term.

Since the function was of the log-log type, the estimated regression coefficients of equation (1) represented elasticities of the value of fish catch; i.e. the responsiveness of fisherman's revenue to percentage
Table 1. Number of fishermen, engines, boats, and fish quantities harvested in Abu Dhabi.

\begin{tabular}{lcccc}
\hline Year & $\begin{array}{c}\text { Number of } \\
\text { fishermen }\end{array}$ & $\begin{array}{c}\text { Number } \\
\text { of marine } \\
\text { engines } \\
\text { offered }\end{array}$ & $\begin{array}{c}\text { Number of } \\
\text { boats }\end{array}$ & $\begin{array}{c}\text { Fish } \\
\text { quantities } \\
\text { harvested } \\
\text { in tons }\end{array}$ \\
\hline 1998 & 4847 & 73 & 1783 & 29534 \\
1999 & 4847 & 111 & 1783 & 30273 \\
2000 & 3051 & 90 & 856 & 34184 \\
2001 & 3488 & 75 & 903 & 42909 \\
2002 & 4827 & 60 & 979 & 30457 \\
\hline
\end{tabular}

changes in the value of the independent variables. The statistical estimation of the alternative TVP function utilized the technique of multiple regression analysis through the implementation of the ordinary least squares (OLS) procedure. Statistical tests, such as the F-ratio, Pvalues, and the student's t-test, were all utilized to test for the significance of the estimated function, the estimated regression coefficients, and the null hypotheses regarding allocative efficiency of input use. The SPSS package was used in fitting data to the model.

\section{Results and Discussion}

Historically, Emirati fishermen were given considerable incentives by the government by way of providing interest-free loans for boat purchases and engines to promote the fishing industry in the country (FAO, 2004). Table 1 shows the changes in the numbers of fishermen in the Emirate of Abu Dhabi from 1998 to 2002. The Table shows that the number of fishermen declined dramatically in the years 2000 and 2001 before climbing back to 4,827 fishermen in 2002. The reasons behind these fluctuations in fishermen numbers, and consequently the numbers of engines, boats, and fish quantities harvested, are probably due to the declarations by the Ministry of Environment and Water (MEW) (formerly known as the Ministry of Agriculture and Fisheries) that governmental support to the fishing industry would gradually decline. Boat engines and maintenance used to be offered for free by the government of the UAE to the fishermen before the year 2000. Thereafter, the government subsidized boat engines by $50 \%$, while the cost of maintenance was totally incurred by fishermen.

In addition, personal interviews with experts of the Marine Resources Research Center, located in Umm AlQuwain, the main marine research institute in the UAE, revealed that Emirati youth were not very interested in working in the fishing industry, and prospective investors were in standby status, waiting to see where government support for the industry would end up. Moreover, aquaculture experts revealed there were informal governmental declarations that the whole industry would be turned over to Emiratis by limiting the number of foreign workers and fishermen to a minimum (Wahba and Anwahi, 2006). 
Table 2. Descriptive statistics of the variables.

\begin{tabular}{|c|c|c|c|c|}
\hline Variable name & Units of measurement & Code & Sample mean & Standard deviation \\
\hline Boat purchase price & AED & BOPR000 & 141.58 & 92.717 \\
\hline License cost & AED & LCOS & 220.76 & 86.343 \\
\hline Boat lifetime & Years & BOLT & 22.31 & 9.026 \\
\hline Maintenance cost & AED/month & MAINMO & 184.51 & 160.430 \\
\hline Boarding cost & $\mathrm{AED} /$ trip/labor & BOARD & 122.96 & 120.219 \\
\hline Cost of importing a laborer & AED & $\mathrm{LABC}$ & 4368.70 & 1118.521 \\
\hline Labor & Number/boat & LABOR & 4.82 & 1.707 \\
\hline Labor salaries & AED/labor/month & SALAR & 712.44 & 205.599 \\
\hline Cost of oil, lubricants, and grease & $\mathrm{AED} /$ month & OIL & 333.47 & 143.166 \\
\hline Cost of ice & $\mathrm{AED} /$ trip & ICE & 143.93 & 102.477 \\
\hline Fishing trips & Number/month & FTIM & 6.30 & 3.872 \\
\hline Fishing days & Number/trip & TDAY & 3.79 & 1.863 \\
\hline Fishing effort & Days & EFFORT & 18.54 & 4.745 \\
\hline Fuel cost & AED/trip & FUELC & 641.76 & 280.086 \\
\hline Total returns & AED/month & RETN & 25225.19 & 15369.947 \\
\hline Boat capacity & Horsepower & BHP & 208.28 & 67.472 \\
\hline Boat length & Feet & BOATL & 32.26 & 14.405 \\
\hline
\end{tabular}

In Abu Dhabi, there are twelve different commercial fish species. The species Lethrinus sp. is the most caught type in terms of both quantity (21,056 tons) and value (AED 210 million) (MEW, 2003).

\section{Descriptive Statistics of the Sample}

Table 2 summarizes the descriptive statistics of all of the variables mentioned. The preliminary examination of the study's cross section random sample of 131 Abu Dhabi fishermen showed the following:

-About $97 \%$ of fishermen were found to be owners of boats; $95 \%$ of the fishermen who owned boats that are priced at AED 300,000 or more were full-time fishermen, and prices of boats ranged from AED 10,000 to more than AED 300,000, with the most expensive boat priced at AED 450,000.

-About $62 \%$ of the fishermen interviewed were found to own only one boat; $53 \%$ of those fishermen were Emiratis, and $41 \%$ were Indians.

-About $5 \%$ of the fishermen interviewed were university graduates, and none claimed to be a full-time fisherman; $35 \%$ of the fishermen were either illiterate or had only primary education.

-The risk encountered in the profession of fishing was concentrated in three main areas/types: fishermen falling from boats, bad weather conditions, and determination of traps sites. Price risk was claimed by fishermen to be due to excess supply of fish, unreliability of foreign labor, low product prices, and spoiled fish. Auctioning (Dallal) was the most common selling method. Winter was claimed to be the favorite season for fishing by almost every individual fisherman due to fish being closer to the shores for warmth.

-Only $10 \%$ of fishermen stated that they did not experience difficulties obtaining fishing licenses, whereas $34 \%$ of fishermen stated that they did not care about the cleanliness of the marine environment.

-Fishermen were found to record no information and data in general, other than those pertaining to monthly revenues.

-Maintenance costs per month ranged between a minimum of AED 25 and a maximum of AED 1000. About 8\% of fishermen insured their boats.

-About $21 \%$ of fishermen used nets, $7 \%$ used lines, and $72 \%$ used traps (gargour) as their main fishing method.

-About 53\% used large traps, 14\% used average sized traps, and only $5 \%$ used small traps. The price of the traps ranged between AED 90 and AED 250. The minimum and the maximum trap numbers used by the typical fisherman in the sample were found to be 20 and 350 traps, respectively.

-The numbers of boats run on diesel and petrol (gasoline) were estimated at 89 boats and 42 boats, respectively; $94 \%$ of fishermen revealed they had advanced equipment on board, with $75 \%$ of boats found to be satellite connected. 
Table 3. Estimated total value product function.

\begin{tabular}{|c|c|c|c|}
\hline Variable & $\begin{array}{c}\text { Value of } \\
\text { estimated } \\
\text { coefficient }\end{array}$ & $\begin{array}{l}\text { Standardized } \\
\text { coefficients }\end{array}$ & Model statistics \\
\hline (Constant) & $\begin{array}{c}2.622 * * \\
(.776)\end{array}$ & & \\
\hline Ln_EFFORT & $\begin{array}{l}.520 * * \\
(.129)\end{array}$ & .190 & $\mathrm{R}^{2}=.810$ \\
\hline Ln_BHP & $\begin{array}{l}.388 * * \\
(.117)\end{array}$ & .151 & \\
\hline Ln_LABOR & $\begin{array}{c}1.264 * * \\
(.122)\end{array}$ & .598 & \\
\hline Ln_BOARD & $\begin{array}{l}.133 * * \\
(.049)\end{array}$ & .124 & F-ratio $=106.389$ \\
\hline Ln_OIL & $\begin{array}{l}.210 * * \\
(.072)\end{array}$ & .123 & \\
\hline
\end{tabular}

Standard errors are between parenthesis.

**Means variable is significant at $\alpha=0.01$.

-Food and boarding expenses for fishermen varied between AED 20 and AED 600 per trip. About $89 \%$ of fishermen interviewed stated that they worked all year round. The number of workers per boat ranged from two laborers to eight laborers maximum. The corresponding salaries ranged from a minimum of AED 400 to a maximum of AED 1100.

-Costs of oils, lubricants and grease ranged from AED 70 to AED 750 per month. Ice consumption ranged from a minimum of AED 20 per trip to a maximum of AED 500 per trip. Water and electricity consumption was found to be free of charge. Fuel costs per trip varied from a minimum of AED 80 to a maximum of AED 990 per month.

- Fishing trips per month (FTIM) ranged from 2 to 22 trips. However, the number of days such trips took (TDAY) ranged from a minimum of one day to a maximum of 8 days. This means the interaction of the two variables FTIM and TDAY, or equivalently the fishing effort (EFFORT), ranged from a minimum of 5 days to a maximum of 24 days per month.

-Monthly fishing revenues varied a great deal amongst fishermen. The minimum was AED 2500 and the maximum was AED 50,000.

-Boat length in feet (BOATL) and boat capacity in horsepower (BHP) were found to be the two main factors determining the price of the boat (BOPR000), whereas both BOATL and BHP were not correlated.
-Boat horsepower (BHP) ranged from a minimum of 75 to a maximum of 350 . Boat lengths varied from a minimum of 10 feet to a maximum of 90 feet.

\section{Total Value Production Function Estimation}

The estimated total value product (revenue) function was as follows:

$$
\begin{gathered}
\ln \_ \text {RETN }=3.00+0.520 \ln \_ \text {EFFORT }+0.388 \ln \_ \text {BHP }+ \\
1.264 \ln \_ \text {LABOR }+0.133 \ln \_ \text {BOARD } \\
+0.210 \text { Ln_OIL } \ldots . . .(2)
\end{gathered}
$$

Other previously-mentioned independent variables that might affect revenues, such as mesh size, trap cost, trap numbers, equipment on board, and cost of fuel used, were of two types. The first pertained to those factors where insufficient data was available. The second type dealt with having enough data on the variable by almost all of the interviewed fishermen. However, answers were so similar to the extent that lack of variations resulted in the factor having no impact on revenue levels. An example of the first type was the factor dealing with mesh size (only 26 fishermen responding). Examples of the second type were trap costs, trap numbers, and equipment on board, where significant variations in answers were not obtained. Table 3 displays the detailed statistical results of the above function, showing strong statistical significance, as represented by the high $\mathrm{R}$-squared and significant F-Ratio and t-statistic.

Table 4 lists the correlation matrix of equation (2) above. This emphasizes partial correlation coefficient of the five independent variables that were statistically significant at the $1 \%$ level; however, the highest partial correlation coefficient of 0.507 was found between the two independent variables fishing effort (ln_Effort) and labor (ln_Labor). This meant that estimated partial correlation coefficients were in the neighborhood of the safe 0.5 range or less. A test of multicollinearity was made to ensure the nonexistence of a serious multicollinearity problem amongst the five explanatory variables. In statistics theory, the two synonymous tests used here were the tolerance values and the Variance Inflation Factor tests (VIF). In addition, the test of the condition indices (Eigen values) was also utilized. Tolerance is defined as (1 $-\mathrm{R} 2$ ), where R2 is the multiple R of a given independent variable regressed on all other independent variables. If the tolerance value is less than some cut-off value, usually 0.20 , the independent variable should be dropped from the analysis due to multicollinearity. This is better than using the simple partial correlation coefficient rule of dropping the independent variable if $r>0.80$, since tolerance looks at the independent variable in relation to all other independents and thus takes interaction effects into account as well as simple correlations. VIF may be used in lieu of tolerance as VIF is simply the reciprocal of tolerance. The rule of thumb is that VIF $>4.0$ when multicollinearity is a problem. Some authors use the more lenient cut-off of VIF $\geq 5$ when multicollinearity is a problem. Condition indices over 15 indicate possible multicollinearity problems and values over 30 indicate serious multicollinearity problems (Wooldridge, 2003). 
Table 4. The correlation matrix of the best fitted total value product function.

\begin{tabular}{|c|c|c|c|c|c|c|c|}
\hline & & Ln_RETN & ln_effort & ln_BHP & ln_labor & ln_board & ln_oil \\
\hline \multirow[t]{3}{*}{ Ln_RETN } & Pearson Correlation & 1 & $.586^{* *}$ & $.532 * *$ & $.864 * *$ & $.498 * *$ & $.325^{* *}$ \\
\hline & Sig. (2-tailed) & & .000 & .000 & .000 & .000 & .000 \\
\hline & $\mathrm{N}$ & 131 & 131 & 131 & 131 & 131 & 131 \\
\hline \multirow[t]{3}{*}{ ln_effort } & Pearson Correlation & $.586 * *$ & 1 & $.364 * *$ & $.507 * *$ & $.315^{* *}$ & -.010 \\
\hline & Sig. (2-tailed) & .000 & & .000 & .000 & .000 & .914 \\
\hline & $\mathrm{N}$ & 131 & 131 & 131 & 131 & 131 & 131 \\
\hline \multirow[t]{3}{*}{ ln_BHP } & Pearson Correlation & $.532 * *$ & $.364 * *$ & 1 & $.473 * *$ & .138 & .097 \\
\hline & Sig. (2-tailed) & .000 & .000 & & .000 & .117 & .272 \\
\hline & $\mathrm{N}$ & 131 & 131 & 131 & 131 & 131 & 131 \\
\hline \multirow[t]{3}{*}{ ln_labor } & Pearson Correlation & $.864 * *$ & $.507 * *$ & $.473 * *$ & 1 & $.486^{* *}$ & $.312 * *$ \\
\hline & Sig. (2-tailed) & .000 & .000 & .000 & & .000 & .000 \\
\hline & $\mathrm{N}$ & 131 & 131 & 131 & 131 & 131 & 131 \\
\hline \multirow[t]{3}{*}{ ln_board } & Pearson Correlation & $.498 * *$ & $.315^{* *}$ & .138 & $.486 * *$ & 1 & .025 \\
\hline & Sig. (2-tailed) & .000 & .000 & .117 & .000 & & .776 \\
\hline & $\mathrm{N}$ & 131 & 131 & 131 & 131 & 131 & 131 \\
\hline \multirow[t]{3}{*}{ ln_oil } & Pearson Correlation & $.325 * *$ & -.010 & .097 & $.312 * *$ & .025 & 1 \\
\hline & Sig. (2-tailed) & .000 & .914 & .272 & .000 & .776 & \\
\hline & $\mathrm{N}$ & 131 & 131 & 131 & 131 & 131 & 131 \\
\hline
\end{tabular}

** Correlation is significant at the 0.01 level (2-tailed).

The estimated regression coefficients represent elasticities of the value of fish catch. For instance, a $10 \%$ increase in the fishing effort results in increasing total revenue by $5.20 \%$; a $10 \%$ increase in the boat's capacity results in increasing revenue by $3.88 \%$; a $10 \%$ increase in the number of laborers on the fishing boat results in increasing revenue by $12.64 \%$; a $10 \%$ increase in the boarding expenses of the fishing crew results in increasing revenues by $1.33 \%$; and a $10 \%$ increase in the amount of money spent on oil, lubricants, and grease results in increasing revenues by $2.10 \%$.

The elasticity estimates obtained for the first three explanatory variables in equation (2), namely Effort, BHP, and Labor are economically rational. As the fishing effort, boat capacity, and number of laborers increase, more revenues may be realized. The rational explanation for the increases encountered in revenues when boarding expenses increase is that when boarding is comfortable and adequate for the crew, a better working atmosphere is availed, which may lead to more devotion to work and consequently better fishing practices. The positive and significant elasticity associated with the oil and lubricants may be an indication of good boat maintenance and consequently less boat problems.

The estimated standardized regression coefficients (Beta) showed that labor was the most prominent factor affecting the fishermen's revenue, followed by the fishing effort, the boat capacity, boarding expenses, and oil and lubricants expenses respectively. The five factors accounted for $81.0 \%$ of the variations in the fishermen's revenues.

The statistical examination of the significance of multicollinearity showed that the tolerance values of the three estimated coefficients were above 0.2 (the critical value), meaning no serious multicollinearity. The VIF was below 4 (the critical value) implying, once again, no serious multicollinearity. However, the condition index of the three remaining independent variables (i.e. labor, boarding, and oil and grease) were above the critical value of 30 , indicating some possible multicollinearity problems that may be associated with these inputs (Table 5) (Hutcheson, 1999). However, the F-ratio and t-statistic (Table 3) show the statistical significance of the estimated TVP function and the estimated coefficients of the independent variables, respectively. This significance of the F-ratio, combined with the significance of the student's t-statistic, may show no serious multicollinearity (Wooldridge, 2003).

\section{TVP Function Given Loan Acquisition}

Personal interviews with the fish and marine experts at the Marine Resources Research Center revealed lack of knowledge on the exact amounts fishermen can get should they need to acquire interest-free loans for buying boats or other major fishing equipment. Governmental loans to fishermen were assessed on a case-by-case basis and they 
Table 5. Multicollinearity results of the fish total value product function.

\begin{tabular}{lcc}
\hline Variable & VIF $^{\mathrm{a}}$ & Condition Index \\
\hline (Constant) & - & 1.000 \\
Ln_effort & 1.449 & 11.423 \\
Ln_BHP & 1.353 & 16.999 \\
Ln_labor & 2.186 & 25.570 \\
Ln_board & 1.374 & 38.802 \\
Ln_oil & 1.181 & 69.981 \\
\hline
\end{tabular}

(a) Critical value of the variance inflation factor (VIF) is 4 .

(b) Critical value of the condition index is 30 .

vary from one fisherman to another. The current trend adopted by the MEW is to eliminate loans provision as a general governmental policy (Wahba and Anwahi, 2006) .

A division of the 131 fishermen into two groups was made to distinguish between fishermen who did obtain loans to buy the boats ( 30 fishermen) and those who did not obtain loans to buy their boats (101 fishermen). This was done to see if acquisition of a loan designed for covering the largest investment cost item (the boat purchase) had a significant effect on the corresponding TVP function. Equation (3) shows the TVP function for the 101 fishermen who did not acquire loans:

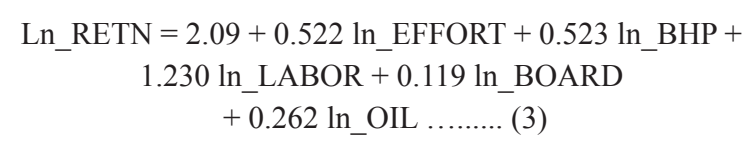

The function is statistically significant wit ${ }^{\mathrm{h}}$ an F-ratio of 83.173 and $\mathrm{R} 2=0.814$ and all of the five explanatory variables statistically significant. Differences in the estimated regression coefficients from the original estimated revenue function (equation 2) were negligible. In other words, the function obtained was similar to that accounting for all fishermen interviewed. This was, however, not the case for the small group of fishermen who acquired loans, however, where the estimated TVP function was statistically insignificant.

\section{Assessment of Price Efficiency of Input Use}

The assessment of price (allocative) efficiency for the five inputs that possessed the most significant impact on TVP for the whole sample of fishermen required the estimation of the marginal value product (MVP) for each of the five said inputs and contrasting that to the corresponding marginal input cost (MIC) for each of them as a ratio. If the ratio of the MVP of the input is equal to its corresponding MIC, then the input is optimally utilized, i.e. the amount of the input used is the profit-maximizing level. However, if the ratio is greater than one or less than one, then the said input is under-utilized or over-utilized respectively. The MVP of the input is the outcome of multiplying the inputs estimated regression coefficients obtained from the TVP function by the ratio of the average :TVP and average input level as in he following equation

$$
\operatorname{MVPx}=\beta^{*}(\text { average TVP/average } \mathrm{X}) \ldots \ldots
$$

where MVPx is the MVP of the input $X, \beta$ is the estimated regression coefficient of the said input $\mathrm{X}$, TVP is Total Value Product, and $\mathrm{X}$ is the level of the input used.

Table 6 shows the estimated $\mathrm{MV}_{\mathrm{P}} \mathrm{x}$ and the corresponding MICx for the five mentioned inputs. The MIC for labor is the average monthly salary the laborer

Table 6. Calculations of the marginal value product of the inputs and its corresponding marginal input cost.

\begin{tabular}{|c|c|c|c|c|}
\hline $\operatorname{MVP}_{\mathrm{x}}$ & $\mathrm{MVP}_{\mathrm{x}}$ calculation & $\operatorname{MVP}_{\mathrm{x}}($ Dirhams $)$ & $\mathrm{MIC}_{\mathrm{x}}$ calculation & $\mathrm{MIC}_{\mathrm{x}}$ (Dirhams) \\
\hline EFFORT & $(0.522) *(25,225 / 18.45)$ & 713.610 & $(712.44+4439) /(18.542)$ & 277.856 \\
\hline BHP & $(0.523) *(25,225 / 208.28)$ & 63.341 & $\begin{array}{l}\text { (1) }(676.9 / 267.664) \\
\text { (2) }(711.0 / 267.664)\end{array}$ & $\begin{array}{l}\text { (1) } 2.529 \\
\text { (2) } 2.656\end{array}$ \\
\hline LABOR & $(1.230) *(25,225 / 4.82)$ & 6437.133 & $\mathrm{NA}^{\mathrm{a}}$ & 712.44 \\
\hline BOARD & $\begin{array}{c}(0.119) * \\
(25,225 / 122.96)\end{array}$ & 24.412 & NA & 122.96 \\
\hline OIL & $\begin{array}{c}(0.262) * \\
(25,225 / 333.47)\end{array}$ & 19.818 & NA & 333.47 \\
\hline
\end{tabular}

aNA - Not applicable. 
Table 7. Assessment of price efficiency of the most prominent inputs affecting total value product for the fishermen.

\begin{tabular}{lll}
\hline Input name & Ratio of $\left(\mathrm{MVP}_{\mathrm{x}} / \mathrm{MIC}_{\mathrm{x}}\right)$ & Input status \\
\hline EFFORT & $(659.811 / 277.856)=2.375$ & Under-utilized \\
BHP & $(1)(40.451 / 2.529)=15.995$ & Under-utilized \\
& $(2)(40.451 / 2.656)=15.230$ & \\
LABOR & $(7892.030 / 712.44)=11.077$ & Under-utilized \\
BOARD & $(24.412 / 122.96)=0.199$ & Over-utilized \\
OIL & $(19.818 / 333.47)=0.059$ & Over-utilized \\
\hline
\end{tabular}

obtained (Table 2). The MIC for the fishing effort is the outcome of dividing the average labor salaries and the skipper's salary by the average fishing effort. The MIC for the boat capacity can be made in two ways: (1) either the outcome of dividing the average boat purchase price (BOPR) by the average boat capacity used in horsepower (BHP) yields the price per the single horsepower (PPHP); then this PPHP is divided by the boat lifetime in months (BOLTM) to obtain the price per horsepower per month (PPHPM), or (2) directly utilizing the BHP regression coefficient (0.711) obtained from an estimated boat price function not reported here which regressed boat purchase price on boat length and boat horsepower, divided by the BOLTM, which is the boat lifetime in months to get the price (cost) of the single horsepower per month. The MIC for the boat boarding variable is the average boarding expenses experienced in the fishing boats, whereas the MIC for the oil and lubricants variable is the average oil, lubricants, and grease expenses spent on fishing boats of the sample (Table 2).

Table 7 shows the assessment of (allocative) price efficiency for the five mentioned variables. The Table shows that none of the five inputs was optimally used. The three inputs (effort, boat capacity, and labor) were all under-utilized in varying degrees since their MVPs outweighed their corresponding MICs, with fishing effort being the closest input to optimal utilization. The two other inputs, namely boarding of the fishing crew and the expenses on oil, lubricants, and grease, were both significantly over-utilized. This is because their MVPs were far less than their corresponding MICs. Since the five ratios were significantly far from one, there was no need to conduct a "t-statistic" to test the null hypothesis that the ratio of VMP of the input to the input's MIC is equal to one.

\section{Conclusions}

Since $32 \%$ of UAE's fish production is concentrated in the Emirate of Abu Dhabi, the examination of the status of fishermen in this Emirate is of importance to policy makers in the Ministry of Environment and water (MEW) and is anticipated to be indicative of the status of the whole fishing industry in the UAE. This cross-sectional study is an exploratory examination of the industry and further studies are needed.

The study came up with the following conclusions and results: (1) About half of the interviewed fishermen (53\%) were Emiratis, contrary to the common belief that nationals are the minority in the Abu Dhabi fishing industry. This is a large percentage of nationals for a given industry in the UAE, where nationals compose only $20 \%$ of the resident population. This necessitates more attention from the MEW to the livelihood and economic wellbeing of fishermen in the form of providing information to fishermen and concerned scientists and researchers; (2) Labor, fishing effort, boat capacities, fishing crew boarding, and oils and lubricants respectively were the five variables that had a major impact on the value of the fish catch (revenues) in Abu Dhabi for the whole sample of fishermen interviewed. These five variables accounted for 81 percent of the variations in fishing revenues. However, none of the five inputs was found to be optimally utilized. Fishing effort, boat capacity, and labor were all underutilized to varying degrees, with the first variable closest to being optimally utilized. Boat boarding expenses and oil and lubricants expenses were both found to be greatly over-utilized, and (3) The fishing boat was found to be the largest investment item for the interviewed fishermen. Unfortunately, because of the inadequate sample size of fishermen who acquired loans, no significant conclusions could be made of the impact of loan acquisition on fishing revenue. However, the total revenue function for the fishermen who did not acquire loans for boat purchase was very similar to that of the total sample.

\section{Acknowledgment}

Financial support for this research was provided by the Research Affairs Sector of the UAE University through grant \# 01-03-6-11/06.

\section{References}

Eggert, H. 2000. Technical inefficiency and its determinant factors in a demersal trawl fishery: The Swedish Norway lobster fishery. Paper presented at the 10th Annual Conference of the European Association of Environmental and Resource Economists, University of Crete, Rethymnon, Greece.

Egna, H.S. and C.E. Boyd (Editors). 1997. Dynamics of Pond Aquaculture. CRC Press.

Esmaeili, A. 2006. Technical efficiency analysis for the Iranian fishery in the Persian Gulf. ICES Journal of Marine Science: Journal du Conseil 63:1759-1764.

Food and Agriculture Organization of the United Nations. 2003. FAO Yearbook of Fishery Statistics Vol. 82. FAO Fisheries Series No. 50. FAO, Rome.

Food and Agriculture Organization of the United Nations. 2004. The International Plan of Action for the Management of Fishing Capacity. FAO, Rome. 
Grafton, R.Q. and D.E. Lane. 1998. Canadian Fisheries Policy: Challenges and Choices. Canadian Public Policy 24:33-47.

Gupta, G.S. 1983. Production Function and Optimum Input Mix in Fish Farming in India. No 464, IIMA Working Papers from Indian Institute of Management Ahmadabad. Research and Publication Department, IIMA.

Hutcheson, G. and N. Sofroniou. 1999. The Multivariate Social Scientist: Introductory Statistics Using Generalized Linear Models. Thousand Oaks, CA: Sage Publications.

Jolly, C.M. and H.A. Clonts. 1993. Economics of Aquaculture. The Haworth Press.

Ministry of Environment and Water. 2003. Annual Statistical Bulletin. Dubai.
United Arab Emirates. Ministry of Environment and Water. 2004. UAE Agriculture Information Centre.http: //www.uae.gov.ae/uaeagricent/STATIS TICS/ fisheries.htm and http://www.uae. gov.ae/uaeagricent/ FISHERIES/fishasfood_e.stm.

Ruseski, G. 1998. International Fish Wars: The strategic roles for fleet licensing and effort subsidies. Journal of Environmental Economics and Management 36:70-88.

Wahba, O.M. and A.A. Anwahi. 2006. Coral reefs and marine protected area experts. Marine Resources Research Center. Umm Al-Quwain, UAE. Personal communications.

Wooldridge, J.M. 2003. Introductory Econometrics. Thompson/Southwestern.

Received: June 2007

Accepted: March 2008 